\title{
Starch processing wastage as a feed for Holstein bulls
}

\author{
A Pirzadeh Naeiny ${ }^{1}$, A. A Khadem ${ }^{1}$, M Rezaeian ${ }^{2}$, A Afzalzadeh ${ }^{1}$ \\ ${ }^{1}$ University of Tehran, Pakdasht/Tehran, Islamic Republic of Iran \\ ${ }^{2}$ University of Tehran, Tehran, Islamic Republic of Iran \\ Email:am4pi@yahoo.com
}

Introduction Industrial wastes comprise a vast range of organic matters which is usually considered useless and an environmental pollution, while most of them have high nutritional value and could be used in livestock nutrition. The waste remained after separating starch and gluten from wheat flour in starch processing factories is one of these valuable and nutritious feeds. In this experiment, a mixture made from starch processing waste, wheat bran and salt by a commercial name of "Powerfeed" was used in Holstein bulls fattening rations to investigate their performances.

Material and methods Twenty-one Holstein bulls were randomly assigned to three groups so that the mean live weights of each of the 7 bulls in each group were almost the same. Bulls in group 1 (control) were fed with a total mixed ration (TMR) comprising of $24 \%$ alfalfa hay, $34 \%$ barley grain, $11 \%$ barley straw, $7 \%$ rapeseed meal, $5 \%$ wheat bran, $11 \%$ corn silage, $7 \%$ beet pulp, $0.6 \%$ mineral-vitamin supplement and $0.4 \%$ sodium bicarbonate to met their energy and protein requirements according to the NRC 2001. For the TMR of bulls in groups 2 (5\% Powerfeed) and 3 (10\% Powerfeed), barley grain was replaced with Powerfeed at amounts of 5\% and 10\% respectively. Bulls in each group were housed in their individual boxes with free access to the fresh water. The experiment lasted 105 days comprising 15 days adaptation and 90 days of fattening. The TMR was fed to the bulls twice a day at 08:00 and 20:00 hours so that they could obtain their feed requirements at ad-lib levels. The body weight of bulls was measured at 30-day intervals and their relative feed conversion ratios were then measured. Data were analyzed using the GLM procedure of SAS 2001.

Results The dry matter content and the crude protein (CP), calcium, phosphorus, sodium, crude fibre and the fat composition of Powerfeed used in this study were: 890, 157, 11.2, 11.2, 30.3, 56.1 and 33.7 g/kg, respectively. As Table 1 shows, there were no significant differences in daily feed intake, average daily gain and the feed conversion ratio of bulls in control group compared to those in bulls of $5 \%$ and $10 \%$ Powerfeed groups.

Table 1 The effect of Powerfeed contained total mixed rations on the performances of Holstein bulls

\begin{tabular}{lllll}
\hline \hline \multirow{2}{*}{ Items } & \multicolumn{3}{c}{ Treatments } \\
\cline { 2 - 5 } & Control & $5 \%$ Powerfeed & $10 \%$ Powerfeed & SEM \\
\hline Daily feed intake $(\mathrm{Kg})$ & 12.3 & 12.4 & 12.2 & 0.26 \\
Average daily gain $(\mathrm{g})$ & 766.1 & 808.0 & 748.9 & 39.3 \\
Feed conversion ratio & 21.6 & 17.4 & 17.7 & 2.15 \\
Average start weight $(\mathrm{Kg})$ & 246.0 & 253.1 & 248.7 & 11.4 \\
Average finish weight $(\mathrm{Kg})$ & 321.9 & 331.1 & 322.9 & 12.1 \\
\hline \hline
\end{tabular}

Conclusion Since the daily feed intake, average daily gain and the feed conversion ratio of Holstein bull calves were not affected by the use of this supplement as part of their total mixed rations in this study and due to the relatively lower feed expenses paid for Powerfeed compared to that for barley grain in Iranian feed markets, the use of Powerfeed (especially at $5 \%$ level) in bull calves fattening rations is recommended.

Acknowledgements The financial support from the Veterinary Research Unit of University of Tehran is gratefully acknowledged.

References

NRC. 2001. Nutrient requirements of dairy cattle. The 7th rev. ed. Natl. Acad. Sci., Washington, DC. 